\title{
Impacts of mean dynamic topography on a regional ocean assimilation system
}

\author{
C. Yan ${ }^{1,2}$, J. Zhu ${ }^{1}$, and C. A. S. Tanajura ${ }^{3}$ \\ ${ }^{1}$ International Center for Climate and Environment Sciences, Institute of Atmospheric Physics, \\ Chinese Academy of Sciences, 100029 Beijing, China \\ ${ }^{2}$ State Key Laboratory of Acoustics, Institute of Acoustics, Chinese Academy of Sciences, 100190 Beijing, China \\ ${ }^{3}$ Dept. de Física da Terra e do Meio Ambiente, Instituto de Física (UFBA), 40170-290 Salvador, Brazil \\ Correspondence to: C. Yan (ycxlasg@mail.iap.ac.cn)
}

Received: 8 May 2015 - Published in Ocean Sci. Discuss.: 15 June 2015

Revised: 8 September 2015 - Accepted: 2 October 2015 - Published: 14 October 2015

\begin{abstract}
An ocean data assimilation system was developed for the Pacific-Indian oceans with the aim of assimilating altimetry data, sea surface temperature, and in situ measurements from Argo (Array for Real-time Geostrophic Oceanography), XBT (expendable bathythermographs), CTD (conductivity temperature depth), and TAO (Tropical Atmosphere Ocean). The altimetry data assimilation requires the addition of the mean dynamic topography to the altimetric sea level anomaly to match the model sea surface height. The mean dynamic topography is usually computed from the model long-term mean sea surface height, and is also available from gravimetric satellite data. In this study, the impact of different mean dynamic topographies on the sea level anomaly assimilation is examined. Results show that impacts of the mean dynamic topography cannot be neglected. The mean dynamic topography from the model long-term mean sea surface height without assimilating in situ observations results in worsened subsurface temperature and salinity estimates. Even if all available observations including in situ measurements, sea surface temperature measurements, and altimetry data are assimilated, the estimates are still not improved. This proves the significant impact of the MDT (mean dynamic topography) on the analysis system, as the other types of observations do not compensate for the shortcoming due to the altimetry data assimilation. The gravimeter-based mean dynamic topography results in a good estimate compared with that of the experiment without assimilation. The mean dynamic topography computed from the model long-term mean sea surface height after assimilating in situ observations presents better results.
\end{abstract}

\section{Introduction}

The launch of many altimetric satellites has provided highquality sea level variation data with nearly global coverage. This is very useful, especially for those areas where in situ observation networks (such as the expendable bathythermographs (XBT) and the Tropical Atmosphere Ocean (TAO) and Array for Real-time Geostrophic Oceanography (Argo) float arrays) are poorly established. Although altimetry data provide only sea surface information, they are in fact associated with subsurface thermohaline structures (Hurlburt, 1984; Carnes et al., 1990). To better understand the surface and subsurface ocean states, a data assimilation technique that optimally combines various measurements with the ocean model is important.

The assimilation of altimetry data along with conventional observations into an ocean model may reproduce ocean processes such as mesoscale circulations, mesoscale eddies, temporal and spatial evolution of eddies, sea level variations, and tropical instability waves (Oschlies and Willebrand, 1996; Carton et al., 1996, 2000; Fujii and Kamachi, 2003; Oke et al., 2005, 2008; Xiao et al., 2008; Xie et al., 2011). Moreover, sea surface temperature (SST) predictions in the marginal seas, El Niño-Southern Oscillation (ENSO) simulations and predictions, and some operational ocean forecast systems are greatly improved with the assimilation of altimetric sea level observations (Fischer et al., 1997; Smedstad et al., 2003; Brasseur et al., 2005; Martin et al., 2007; Zheng et al., 2007; Bertino and Lisæter, 2008; Zhu et al., 2011). 
Altimeter data provide information on sea level anomalies (SLAs) relative to a long-term mean sea surface height (MSSH) rather than on absolute sea levels. The time average of the sea surface referenced to the earth's geoid is called the mean dynamic topography (MDT). For an ocean model, the MSSH and MDT are equivalent since the geoid is a sphere. When altimeter measurements are assimilated, the MDT is required to add the SLA observations for comparisons with the model's sea surface heights. The choice of MDT is very important. Segschneider et al. (2000) examined the sensitivity of the ocean forecasting system to the MDT and found that different MDTs induced significant variations in the $100 \mathrm{~m}$ temperature (up to $5^{\circ} \mathrm{C}$ ) and in the thermocline depth (up to about $37 \mathrm{~m}$ ) in the Nino-3 area. Storto et al. (2011) showed that a good MDT may improve the verification skill scores of temperature and salinity in tropical regions. Xu et al. (2012) proposed a new MDT and applied it in the SLA assimilation of the South China Sea.

This paper investigates the impacts of different MDTs on an ocean assimilation system based on the ensemble method for the Pacific-Indian oceans. The structure of this paper is as follows. Section 2 describes the assimilation system, including the ocean model, assimilation methods, and multisource observations. In Sect. 3, different MDTs are compared. In Sect. 4, we present the impacts of different MDTs on the subsurface temperature and salinity in the SLA assimilation and investigate whether the impacts are present when all available observations are assimilated. Section 5 presents some results.

\section{The assimilation system}

\subsection{Model}

The Hybrid Coordinate Ocean Model (HYCOM), developed from the Miami Isopycnic Coordinate Ocean Model (MICOM; Bleck, 2002; Chassignet et al., 2007), is used in this paper. It is characterized by a hybrid vertical coordinate that transfers smoothly from the isopycnal coordinate in the open, stratified ocean to the terrain-following sigma coordinate in the coastal regions and to the $z$ coordinate in the mixed layer and unstratified seas. Such a setup may reasonably simulate coastal or open-sea ocean states by combining the advantages of different types of coordinates. The K-profile parameterization (KPP) vertical mixing scheme (Large et al., 1994; Peters et al., 1988) is included in HYCOM.

The model domain spans the Pacific and Indian oceans from 27 to $290^{\circ} \mathrm{E}$ and from $50^{\circ} \mathrm{S}$ to $60^{\circ} \mathrm{N}$ with a spatial resolution of about $1 / 3^{\circ} \times 1 / 3^{\circ} \times 26$ vertical hybrid layers. The HYCOM is forced by the 6-hourly fields from the ERAinterim, including temperature, dew point temperature, mean sea level pressure, and wind. The lateral boundary conditions and sea surface salinity fields are relaxed toward monthly cli- matologies taken from the Generalized Digital Environmental Model (GDEM; Teague et al., 1990).

\subsection{Assimilation method}

The assimilation method used in this paper is the Ensemble Optimal Interpolation (EnOI) method (Evensen, 2003; Oke et al., 2008). The solution is given by solving the following equation:

$\psi^{\mathrm{a}}=$

$\boldsymbol{\psi}^{\mathrm{b}}+\alpha(\mathbf{C} \cdot \mathbf{P}) \mathbf{H}^{\mathrm{T}}\left(\alpha \mathbf{H}(\mathbf{C} \cdot \mathbf{P}) \mathbf{H}^{\mathrm{T}}+\mathbf{R}\right)^{-1}\left(\boldsymbol{\psi}^{\mathrm{o}}-\mathbf{H} \boldsymbol{\psi}^{\mathrm{b}}\right)$,

where $\psi=(u, v, d, t, s, p b, u b, v b)$ represents the model state vector including baroclinic current fields, layer thickness, temperature, salinity, barotropic pressure, and barotropic current fields. The superscripts $a, b, o$, and $\mathrm{T}$ denote analysis, background, observation, and matrix transpose, respectively. $\mathbf{P}$ is the background error covariance matrix. $\mathbf{R}$ is the observation error covariance matrix. $\mathbf{H}$ is the observation operator that maps from the model space to the observation space. $\mathbf{C}$ is a correlation function used to localize the background error covariances. The circle between $\mathbf{C}$ and $\mathbf{P}$ denotes a Schur product. $\alpha$ is a scalar used to tune the magnitude of the covariance. Here, it is taken as 0.4 .

The background error covariance matrix $\mathbf{P}$ is estimated by $\mathbf{P}=\frac{\mathbf{A} \mathbf{A}^{\mathrm{T}}}{(n-1)}$,

where $\mathbf{A}$ is an ensemble anomaly taken from the long-time model integration and $n$ is the ensemble size ( $n=120$ here). Each member of the ensemble consists of all the model variables included in Eq. (2). To retain the season dependence of the background error covariance, different ensembles in different seasons are adopted in this paper. In other words, for each season, the ensemble is randomly sampled from the multiyear model outputs in the corresponding season.

The EnOI may be used to assimilate the sea level anomaly, sea surface temperature, and in situ observations. Due to the isopycnic coordinate included in HYCOM, a different technique (Xie and Zhu, 2010) based on the EnOI is used to assimilate the temperature and salinity observations. The layer thickness computed from temperature and salinity observations is assimilated to adjust the model layer thickness, current, and barotropic pressure fields. Then, the temperature or salinity observations are assimilated to adjust the model temperature or salinity followed by diagnosing the salinity or temperature from the equation of the seawater state.

\subsection{Observations}

The in situ measurements include vertical temperature and salinity profiles from different instruments such as expandable bathythermographs (XBT), buoys, sea stations, and 
Argo floats. These observations are taken from the Met office Hadley Centre observations data set (EN3 version2a) within the framework of the European Union ENSEMBLES project. This data set has been quality checked (Ingleby and Huddleston, 2007; Guinehut et al., 2009).

The sea level anomaly data relative to the time average over 1993-1999 with global coverage are taken from maps of merged satellite products provided by the Data Unification and Altimeter Combination System (DUACS) of the Ssalto multi-mission ground segment (SSALTO), and released by the Archiving, Validation and Interpretation of Satellite Oceanographic data (AVISO). The maps of sea level anomalies combining data from many satellites (Jason-2, Jason-1, Topex/Poseidon, Envisat, Geosat Follow-on (GFO), European remote-sensing satellite 1/2 (ERS-1/2), and Geosat) are produced by a global multi-mission crossover minimization for orbit error reduction and the optimal interpolation (OI) for long wavelength errors at a resolution of $1 / 3^{\circ} \times 1 / 3^{\circ}(\mathrm{Le}$ Traon et al., 1998; Ducet et al., 2000). The mapped SLA data set has a wide and homogeneous coverage compared with the along-track SLA. This may avoid the effects of a sparse or nonhomogeneous distribution of SLA on the assimilation.

The sea surface temperature (SST) observations are from the product of Reynolds et al. (2007). It was produced by combining the SST data from the Advanced Very High Resolution Radiometer (AVHRR) and Advanced Microwave Scanning Radiometer (AMSR) satellites with in situ data from ships and buoys using the optimum interpolation (OI) method at a spatial resolution of $1 / 4^{\circ} \times 1 / 4^{\circ}$ and a temporal resolution of 1 day with global coverage.

\section{Mean dynamic topography}

When the altimetric measurements are assimilated, the MDT needs to be known. The MDT is added to the altimetric SLA to obtain the observed sea level, so that it can be compared with the model's sea surface height. In the absence of a precisely observed MDT, a model MDT is usually used. The model MDT is computed from the long-term mean sea surface height of the model.

In this section, we describe and compare three MDTs. One is derived from the MSSH of a model free run without any data assimilation (hereafter called MDTMOD). One is from the MSSH of a model assimilation run with temperature and salinity assimilation only (hereafter called MDTTS), and the third is based on gravimetric data and in situ observations (Rio et al., 2009). The region average of the gravimeter-based MDT is $0.8 \mathrm{~m}$ and is thus much higher than the corresponding model MDTs. An offset should be added such that the gravimeter-based MDT has a spatial average same as that of the MDTTS. The gravimeter-based MDT with the offset removed is called MDTOBS.

Figure 1 shows the maps of the different MDTs. Overall, the three MDTs show a similar spatial structure, with high
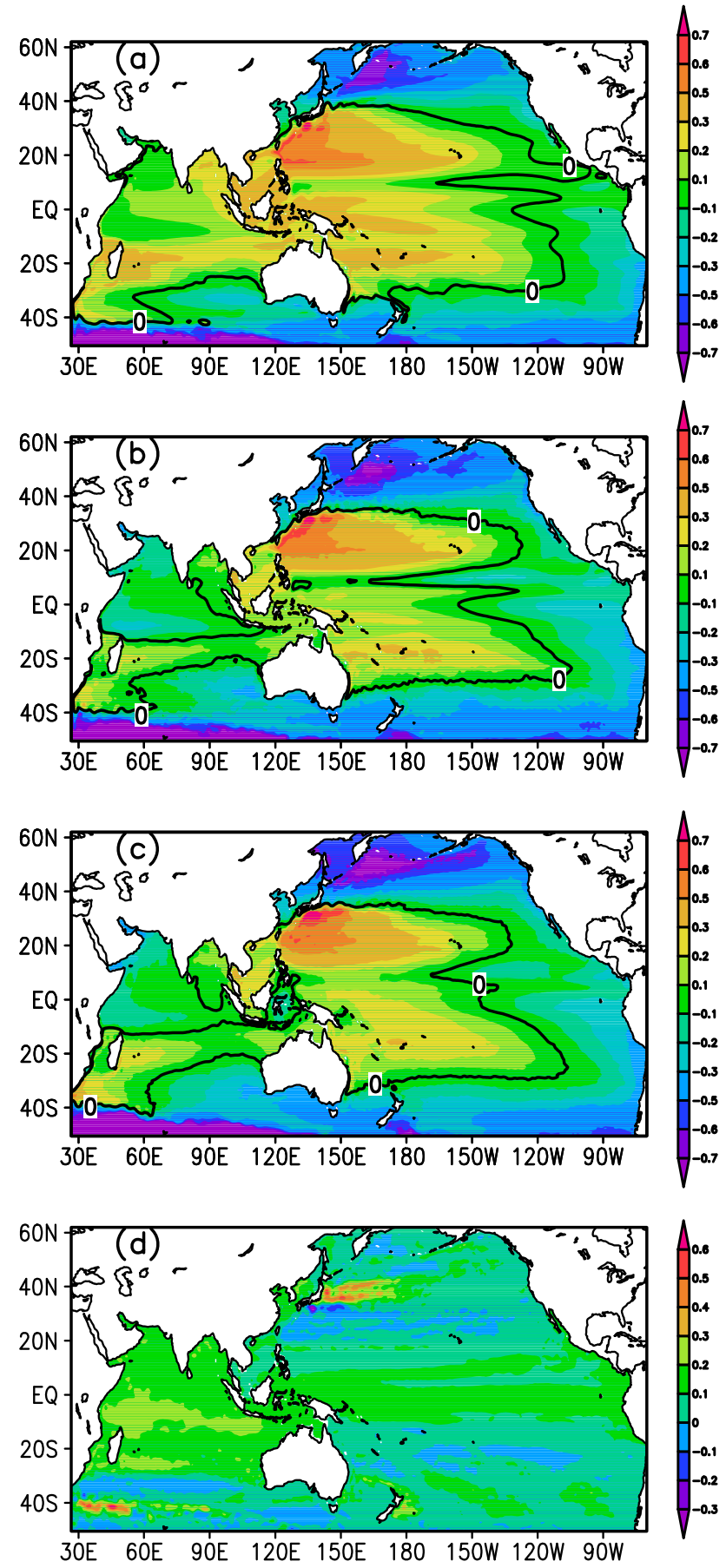

Figure 1. MDTs from a model free run without any data assimilation (MDTMOD) (a), from an assimilation run with in situ data assimilation (MDTTS) (b), and from the gravimetric data and in situ observations with an offset removed (MDTOBS) (c). Difference between MDTMOD and MDTTS (d). Values are given in units of meters. The bold solid line represents isoline 0 .

sea levels in the southern and northern subtropical Pacific, Bay of Bengal, and southwestern Indian Ocean and strong gradients corresponding to the large-scale circulation system 

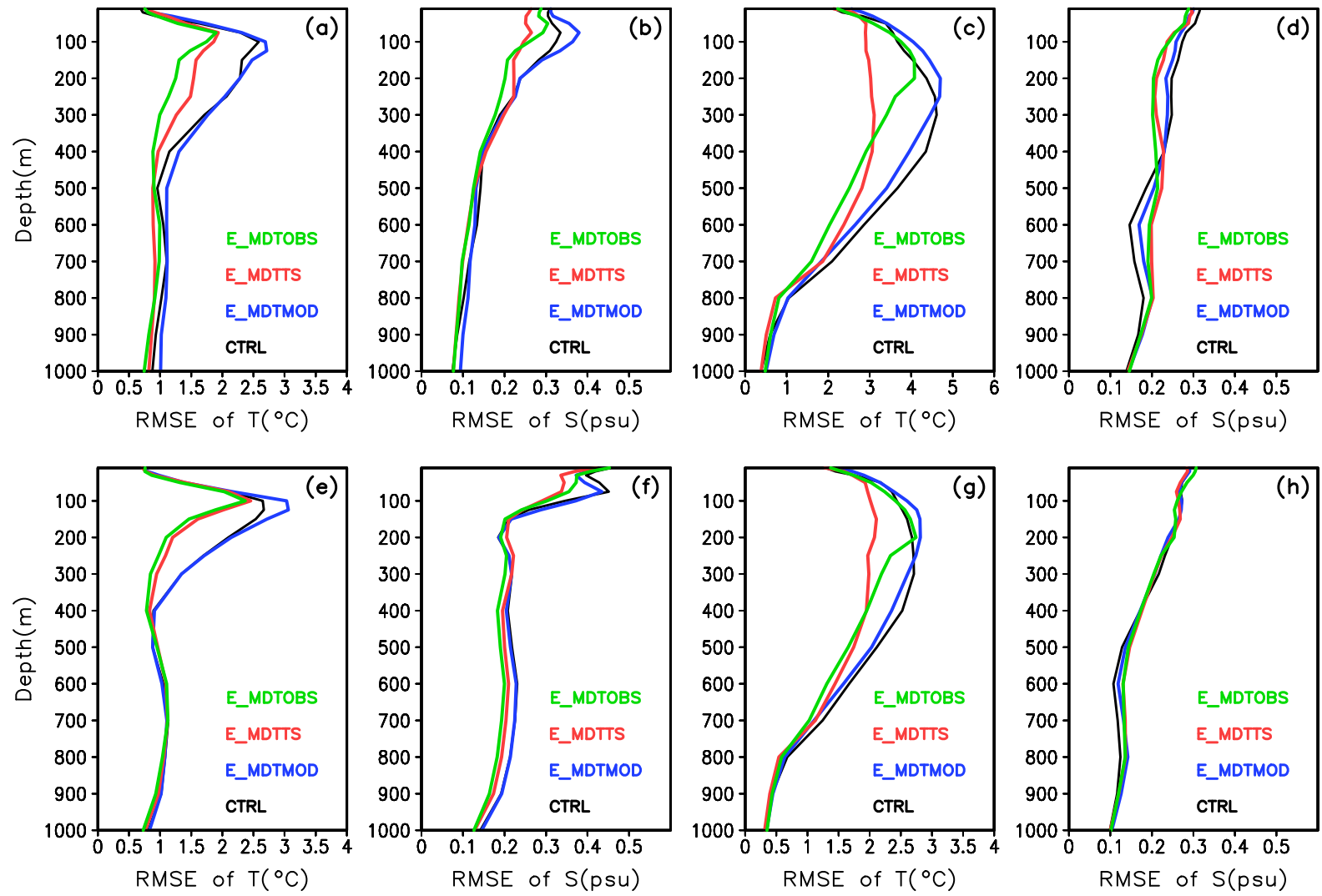

Figure 2. The root mean square errors of temperature (unit: ${ }^{\circ} \mathrm{C}$ ) and salinity (unit: psu) for the southwestern area including the Agulhas current system $(\mathbf{a}, \mathbf{b})$, Kuroshio-current area $(\mathbf{c}, \mathbf{d})$, the Indian Ocean $(\mathbf{e}, \mathbf{f})$, and the Pacific Ocean $(\mathbf{g}, \mathbf{h})$ from different experiments. Black: CTRL; blue: E_MDTMOD; red: E_MDTTS; green: E_MDTOBS.

and western boundary current. The main differences between the MDTMOD and MDTTS are located in the areas of rich eddy activity, such as the Kuroshio extension and Agulhas current systems (Fig. 1d). Moreover, the largest difference reaches up to $60 \mathrm{~cm}$. Additionally, in the northern Indian ocean and equatorial Pacific, the MDTMOD is clearly higher than the MDTTS. In general, the MDTMOD is higher than the MDTTS. That is also implied by the spatial mean of the MDTMOD and MDTTS (0.09 versus $0.02 \mathrm{~m}$ ). This means that the assimilation of temperature and salinity decreases the sea surface height, particularly in the regions of eddy activity. If the gravimeter-based MDT is higher than the model MDT in one place and lower in another place, the offset correction may increase the difference in some places. As a result, the increased difference would lead to a degradation (Vidard et al., 2009). In fact, the gravimeter-based MDT is significantly higher than the other two MDTs over the entire region (figure not given). Therefore, the removal of an offset basically does not lead to a degradation in some regions. The similar spatial structure can be seen for the MDTOBS and the MDTTS.

\section{Results}

The MDT that combines gravimetric data and in situ observations should be more precise than the model MDTs, and it is expected to bring positive impacts on the model state analyses. In this section, we investigate the impacts of the three MDTs in the altimetric SLA assimilation using a same ocean model as that the MDTs derive from.

\subsection{Impacts of different MDTs on SLA assimilation only}

To analyze the impacts of different MDTs when SLA measurements alone are assimilated, we performed four experiments for the period 2005-2007. The experiment without any data assimilation is called CTRL. The experiment that uses the MDTMOD and assimilates SLA observations only is referred to as E_MDTMOD; the experiment using the MDTTS is referred to as E_MDTTS; the experiment using the MDTOBS is referred to as E_MDTOBS.

The Argo floats from EN3 data provide high-quality temperature and salinity profiles. Therefore, this data is used to verify the impacts of different MDTs on temperature and salinity analyses. The vertical distributions of the root mean 

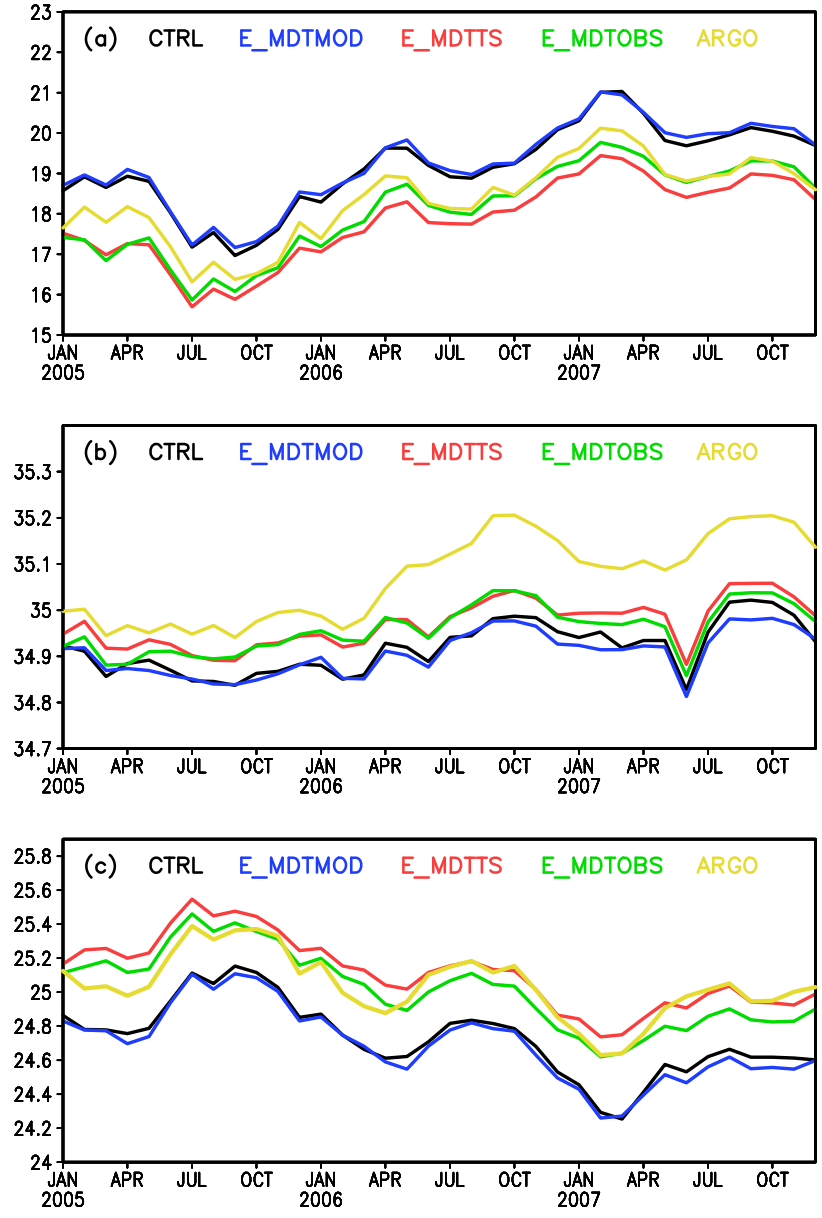

Figure 3. Time series of temperature $\left(\mathbf{a}\right.$; unit: $\left.{ }^{\circ} \mathrm{C}\right)$ salinity (b; unit: psu), and density (c; unit: $\mathrm{kg} \mathrm{m}^{-3}$ ) averaged over the southwestern area including the Agulhas current system and the upper $300 \mathrm{~m}$ from different experiments. Black: CTRL; blue: E_MDTMOD; red: E_MDTTS; green: E_MDTOBS; yellow: Argo.

square errors (RMSEs) against the Argo observations in different areas are shown in Fig. 2. In the eddy-active areas, the impacts of the SLA assimilation using the MDTTS are positive on the temperature and salinity, except for the vertically nonuniform impacts on the salinity of the Kuroshio. Compared with the MDTTS, the use of the MDTMOD leads to greater RMSEs of the temperature and salinity, even greater than the experiment without any data assimilation. The impacts are positive when the MDTOBS is used in the SLA assimilation. In the Indian Ocean, the use of MDTOBS leads to a slightly better result than the MDTTS especially for the temperature. In the Pacific Ocean, the impacts of the MDTTS outperform the MDTOBS for the temperature. The impacts of different MDTs on the temperature and salinity for the entire Indian Ocean or the Pacific Ocean are basically the same as for the dynamically important local areas.

The RMSEs demonstrate the negative or positive impacts of different MDTs on the SLA assimilation but cannot illus-
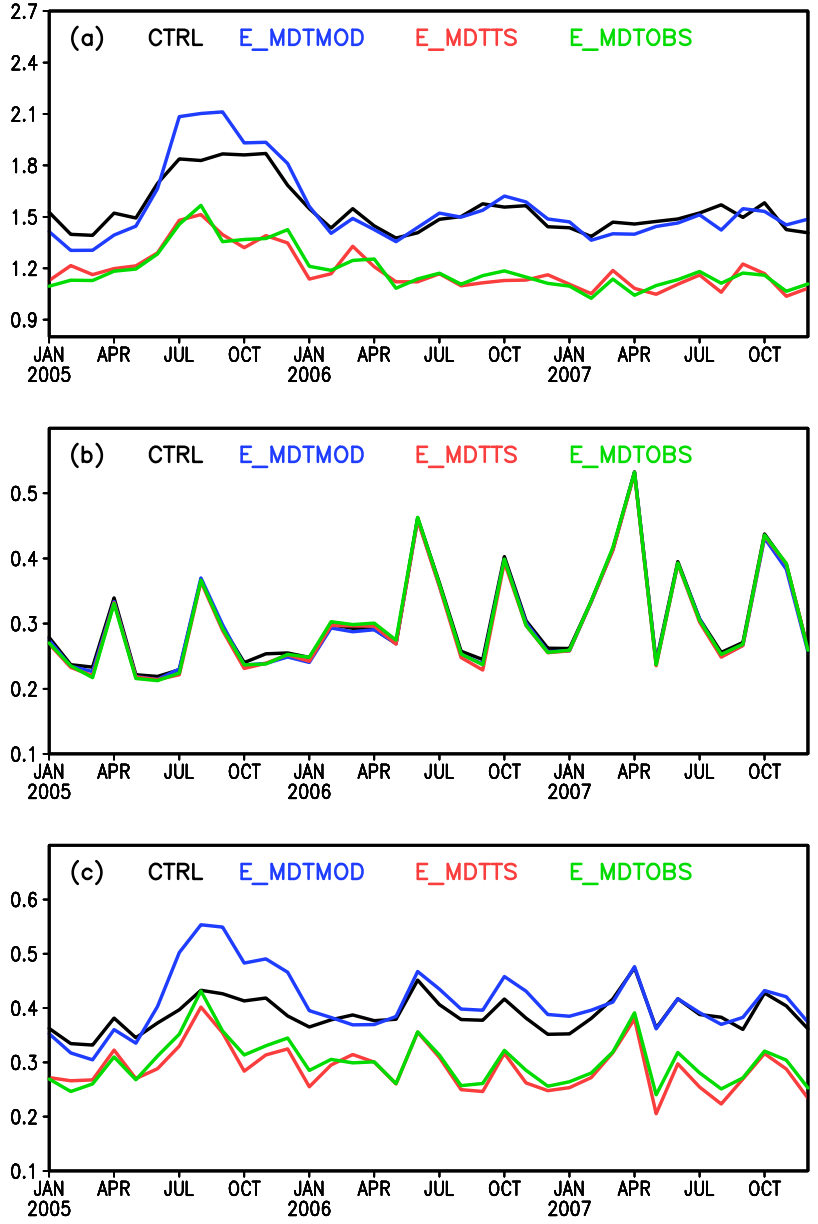

Figure 4. Time series of the RMSEs of temperature (a; unit: ${ }^{\circ} \mathrm{C}$ ) salinity (b; unit: psu) and density (c; unit: $\mathrm{kg} \mathrm{m}^{-3}$ ) averaged over the upper $300 \mathrm{~m}$ in the Pacific-Indian oceans from different experiments. Black: CTRL; blue: E_MDTMOD; red: E_MDTTS; green: E_MDTOBS.

trate the increase or decrease in the temperature or salinity fields. Some hints are given by the time evolution of temperature, salinity, and density averaged over the southwestern area including the Agulhas current system and the upper $300 \mathrm{~m}$ (Fig. 3). The MDTMOD leads to a slight increase in temperature compared with the CTRL. In fact, the temperature from the CTRL is higher than the observations. A good assimilation scheme should produce a decreased analysis in a statistical sense. The use of the MDTMOD induces an opposite trend in temperature variations. The experiment using the MDTTS or the MDTOBS shows a correct adjustment to the temperature. Moreover, the adjustment is larger for the MDTOBS. For the salinity averaged over the first $300 \mathrm{~m}$, the results are similar, but only the magnitude of the modification is not as large as for the temperature. The resultant densities also clearly demonstrate different performances of the different MDTs. 

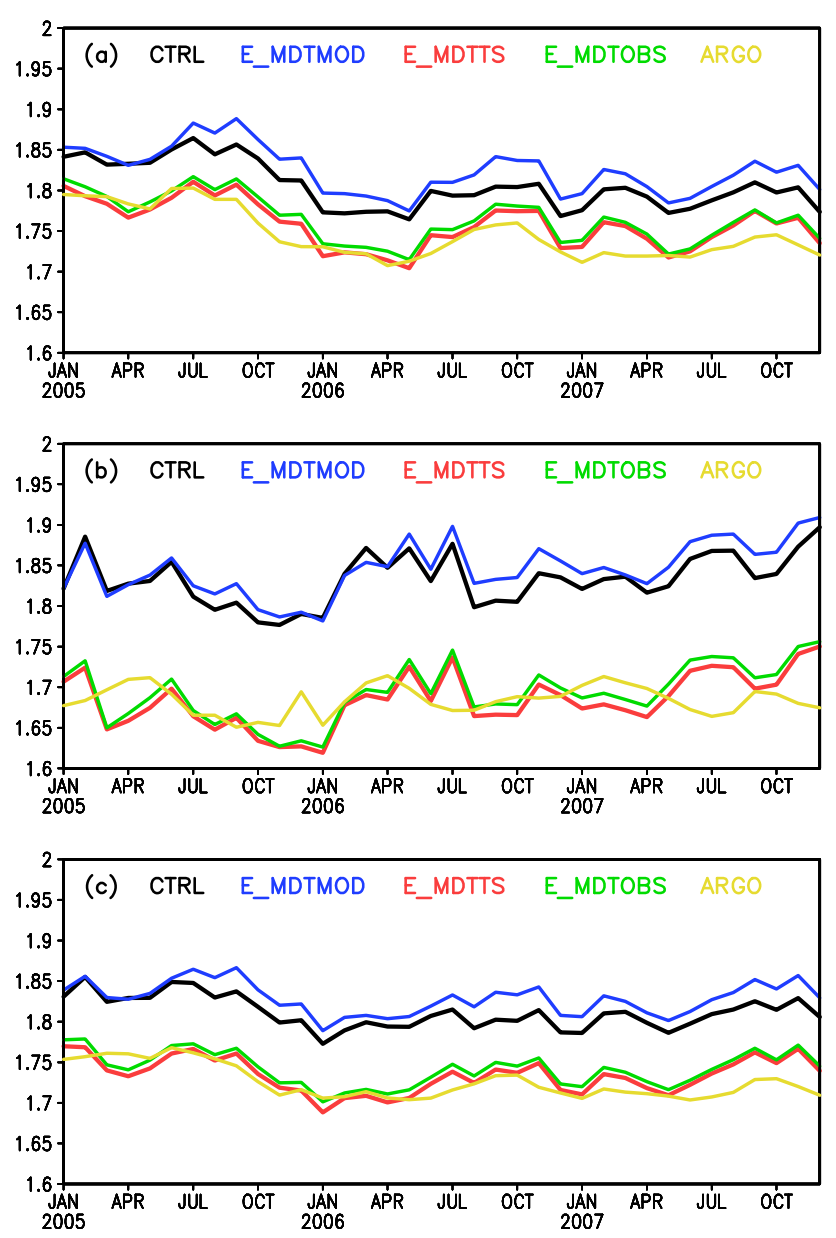

Figure 5. Time series of sea surface dynamic height (unit: $m$ ) averaged over the Pacific Ocean (a), Indian Ocean (b), and IndianPacific oceans (c) from different experiments. Black: CTRL; blue: E_MDTMOD; red: E_MDTTS; green: E_MDTOBS; yellow: Argo observations.

The evolution of the RMSEs over the Indian-Pacific oceans further demonstrates that the impact of the MDTMOD on the temperature is worse than that from the experiment without assimilation, while both MDTTS and MDTOBS show a visible improvement (Fig. 4). There are no evident impacts on the salinity averaged over the upper $300 \mathrm{~m}$ whether the MDTMOD, MDTTS or MDTOBS are used in the SLA assimilation for the entire Pacific and Indian oceans. The differences among the densities in the four experiments are mainly induced by the differences in the temperature.

The sea surface dynamic height ( $\mathrm{SDH}$ ) is affected by the seawater density. Therefore, it is also a factor when evaluating the subsurface temperature and salinity. The SDH is computed by the following function $h$ :

$h(\boldsymbol{T}, \boldsymbol{S})=-\int_{0}^{Z_{m}} \frac{\rho(\boldsymbol{T}, \boldsymbol{S}, p)-\rho_{0}(p)}{\rho_{0}(p)} \mathrm{d} z$, where $\boldsymbol{T}$ and $\boldsymbol{S}$ denote the column vectors of the temperature and salinity variables, respectively. $\rho(\boldsymbol{T}, \boldsymbol{S}, p)$ denotes the density computed from the equation of the seawater state. $\rho_{0}(p)=\rho(0,35, p)$ is the reference density. $Z_{m}$ is the reference depth, taken as $1000 \mathrm{~m}$ here; $z$ denotes the vertical coordinate; $p$ denotes the pressure. The relationship between $p$ and $z$ is given by the hydrostatic equation:

$\frac{\partial p}{\partial z}=-\rho g$,

where $g$ denotes the gravitational acceleration. Figure 5 shows the time series of SDH averaged over different areas, and shows that the Pacific Ocean-averaged SDH is higher than that for the Indian Ocean. The SDH derived from the CTRL is high compared to the observations. For both the Indian and Pacific oceans, the SDH from E_MDTMOD is slightly higher than that from CTRL. This indicates an inaccurate adjustment of subsurface temperature, or salinity, or both. Both E_MDTTS and E_MDTOBS present a better $\mathrm{SDH}$, which is closer to observations.

\subsection{Impacts of different MDTs on the multisource data assimilation}

All the observation-network data, including in situ and remotely sensed observations, are expected to be complementary to each other in order to achieve a better understanding of the ocean. However, it is not certain whether the impacts of all the types of observations on the assimilation are complementary, or whether the assimilation of other types of measurements can remedy the failure of one type of measurement. In order to address this issue, we additionally performed four experiments. One experiment is called E_NO_SLA and assimilates only temperature and salinity profiles. Another experiment is called EALL_MDTMOD; it uses MDTMOD and assimilates all observations consisting of the temperature and salinity profiles from Argo, XBT, conductivity temperature depth (CTD), and TAO as well as SST and SLA from satellites. The other two experiments are called EALL_MDTTS and EALL_MDTOBS; these are the same as the experiment EALL_MDTMOD except that EALL_MDTTS and EALL_MDTOBS use MDTTS and MDTOBS, respectively.

The super-observation is applied to profiles from EN3 before the assimilation. A profile is chosen from the EN3 observations falling in each $3 \times 3$ model grid bin for the assimilation. The selection order is as follows: first an Argo profile, then CTD, then TAO, and finally XBT/MBT (mechanical bathythermograph). Those profiles that are not chosen are used for the validation. Figure 6 shows the performances of the different experiments by the RMSEs of temperature and salinity relative to the independent observations that were not assimilated. For the northeastern Indian Ocean, including the Bay of Bengal, the RMSEs of the temperature for the EALL_MDTMOD are greater than those from the CTRL 

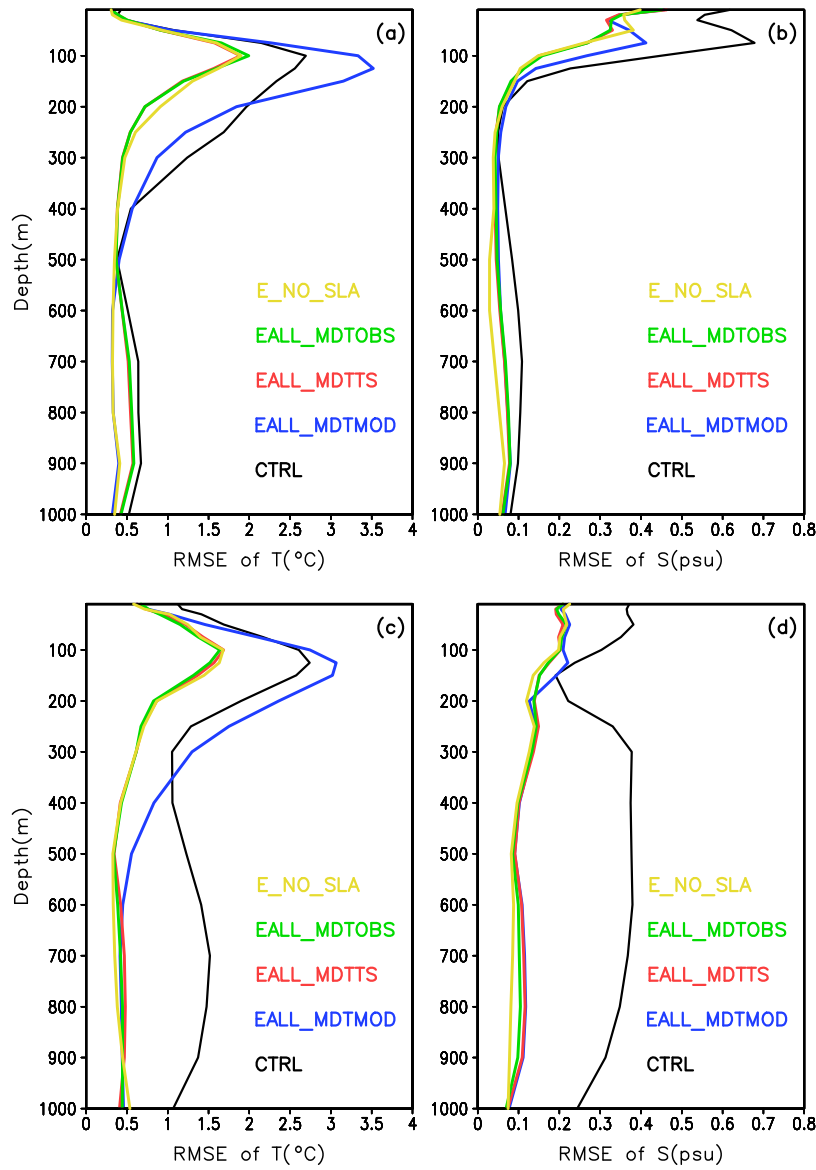

Figure 6. RMSEs of temperature (left; unit: ${ }^{\circ} \mathrm{C}$ ) and salinity (right; unit: psu) from different experiments in the northeastern Indian Ocean including the Bay of Bengal $(\mathbf{a}, \mathbf{b})$ and the northwestern Indian Ocean including the Arabian Sea (c, d). Black: CTRL; blue: EALL_MDTMOD; red: EALL_MDTTS; green: EALL_MDTOBS; yellow: E_NO_SLA.

in the thermocline, while the RMSEs of the salinity are less. The performance of the EALL_MDTTS is same as that of the EALL_MDTOBS, and is better for both the temperature and salinity. The experiment E_NO_SLA in which no SLA observations are assimilated shows a better performance. This further indicates the significant impact of MDT on the assimilation. For the northwestern Indian Ocean including the Arabian Sea, the impacts of different MDTs are similar.

To quantify the contributions of all the observations, we also give the RMSEs of the experiments with the SLA assimilation alone (Fig. 7) for the same areas as in Fig. 6. The RMSEs for the experiments assimilating all the observations are reduced compared to those from the SLA assimilation only, regardless of the use of any MDT. For the MDTOBS, the RMSEs are reduced by about $1{ }^{\circ} \mathrm{C}$ for the temperature and about $0.3 \mathrm{psu}$ for the salinity. This implies that the assimilation of all observations can mitigate the degradation but not remove it entirely. The SDH and averaged temperature
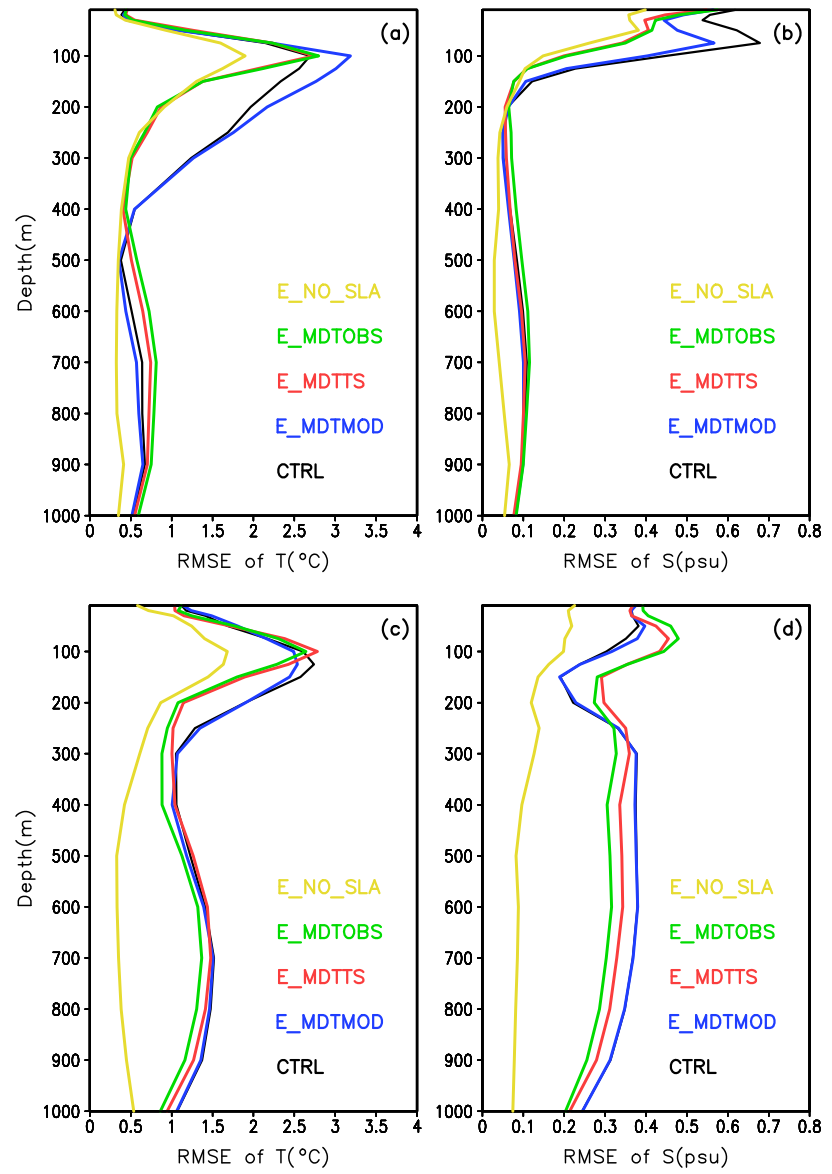

Figure 7. RMSEs of temperature (left; unit: ${ }^{\circ} \mathrm{C}$ ) and salinity (right; unit: psu) from different experiments in the northeastern Indian Ocean including the Bay of Bengal $(\mathbf{a}, \mathbf{b})$ and the northwestern Indian Ocean including the Arabian Sea (c, d). Black: CTRL; blue: E_MDTMOD; red: E_MDTTS; green: E_MDTOBS; yellow: E_NO_SLA.

and salinity over the upper $300 \mathrm{~m}$ also show similar results (figures not given here).

\section{Summary and discussion}

In this study, we investigated the impacts of different MDTs used in the SLA assimilation on the subsurface temperature and salinity by performing a series of experiments.

First, the impacts from the use of different MDTs were analyzed for the case when only the altimetric SLA measurements were assimilated. The MDT derived from a model run without any data assimilation shows a negative impact compared with the experiment without assimilation, especially on the temperature. The MDT derived from the assimilation experiment of in situ observations demonstrates the better performance for both temperature and salinity. When the MDT based on gravimetric data was used in the SLA assimilation, the impacts on the subsurface temperature and salinity 

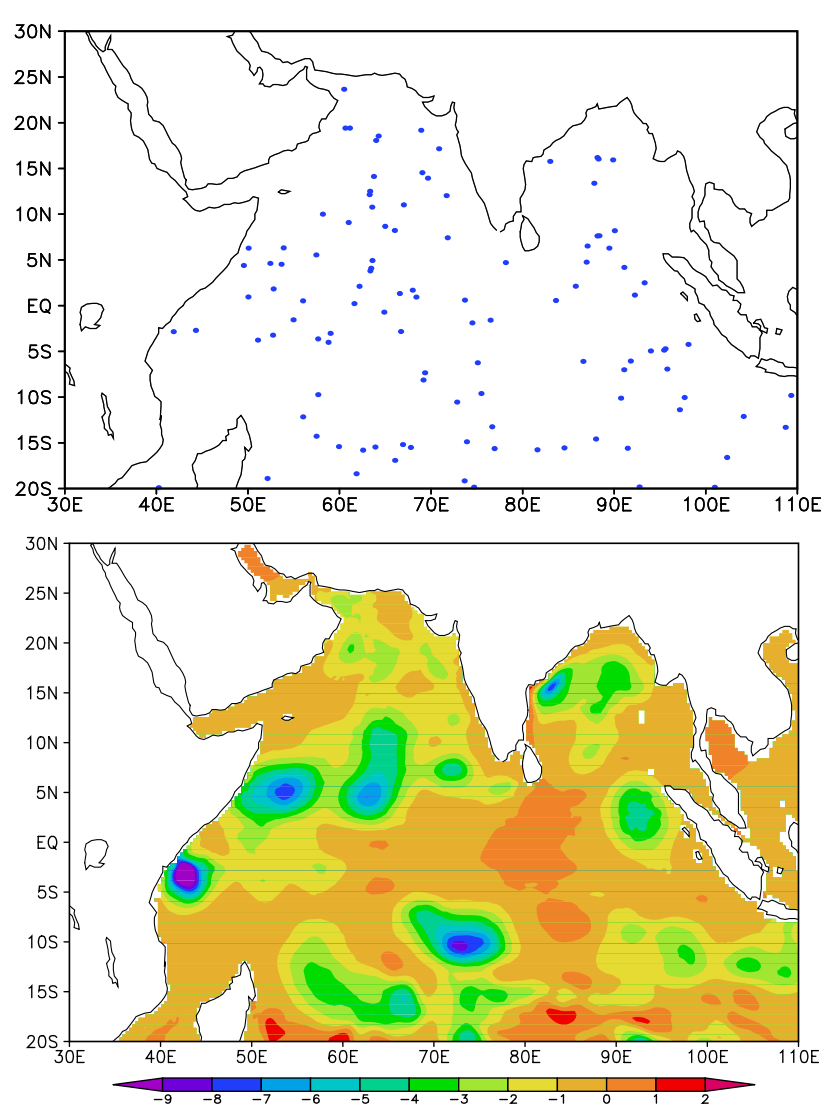

Figure 8. The distribution of Argo floats used in the assimilation (top) and the difference between the SSH (sea surface height) from the Argo assimilation experiment and SSH from the CTRL without any data assimilation (bottom; unit: $\mathrm{cm}$ ).

are also positive and not better than those of the MDTTS in the Pacific Ocean. The fields averaged over the upper $300 \mathrm{~m}$ show that the temperature or salinity fields resulting from the use of the model-derived MDT depart from the observations. This implies that the adjustments to the temperature or salinity from the use of the MDTMOD go in an opposite direction to the observations. The modifications due to the use of the MDTs obtained from the model run assimilating the in situ measurements and the gravimetric observations in the SLA assimilation proceed in the correct direction. The reason for this is probably as follows. In general, the model-derived MDT is higher than the assimilation-runderived MDT and the observed MDT. This means that the observed sea level obtained by adding the corresponding MDT to the SLA measurements becomes higher. As a result, the model temperature (or salinity) increases (or decreases) after the SLA assimilation so that the model sea level fits well with the observed high values for the southwestern Indian Ocean (Fig. 3) according to the theory of expansion and contraction. The SDH induced by the vertical density effect further demonstrates the performance of the different MDTs.
Second, the impacts of different MDTs when all types of measurements, including in situ observations and remotely sensed data, are assimilated was analyzed. The results show that the assimilation of all observations may further enhance the improvement induced by the use of an assimilationderived MDT or observed MDT. Meanwhile, it may also alleviate the deteriorations induced by the SLA assimilation when the model-derived MDTs are used, but it may not eliminate them completely. The possible reasons for this are as follows. When a high MDT based on the model run is used, the SLA assimilation leads to a high model sea level to match the observed equivalent. Meanwhile, the assimilation of in situ observations may decrease the model sea level (Fig. 8). In the areas where Argo floats are located, the SSH (sea surface height) from the Argo assimilation shows a notable reduction. The contradictions between the assimilations of SLA with the use of MDTMOD and in situ observations occur for this reason and are irreconcilable.

When no SLA observations are used in the assimilation, the temperature and salinity fields show a great improvement. This also indicates that the MDT plays a significant role in the assimilation. The MDT from an assimilation run of temperature and salinity observations presents many more advantages in our data system. It actually contains observed information and is consistent with the model's dynamics. Although the observed MDT is relatively accurate, it cannot account for the model's dynamics, and there exist some inconsistencies with the model due to the model's bias. Therefore, based on our analysis, an MDT based on the assimilation of in situ measurements should be considered as the first choice.

Acknowledgements. This research was supported by the Chinese Academy Sciences' Project "Western Pacific Ocean System: Structure, Dynamics and Consequences" (Grant No. XDA11010405), State Key Laboratory of Tropical Oceanography, South China Sea Institute of Oceanology, Chinese Academy of Sciences (Project No. LTO1501), the 973 Program (grant no. 2010CB950401), and the National Natural Science Foundation of China (grant no. 41176015).

Edited by: E. J. M. Delhez

\section{References}

Bertino, L. and Lisæter, K. A.: The TOPAZ monitoring and prediction system for the Atlantic and Arctic Oceans, J. Operat. Oceanogr., 2, 15-18, 2008.

Bleck, R.: An oceanic general circulation model framed in hybrid isopycnic-cartesian coordinates, Ocean Model., 4, 55-88, 2002.

Brasseur, P., Bahurel, P., Bertino, L., Birol, F., Brankart, J.-M., Ferry, N., Losa, S., Rémy, E., Schröter, J., Skachko, S., Testut, C.-E., Tranchant, B., van Leeuwen, P. J., and Verron, J.: Data Assimilation for marine monitoring and prediction: The Mercator operational assimilation systems and the MERSEA developments, Q. J. R. Met. Soc., 131, 3561-3582, 2005. 
Carnes, M. R., Mitchell, J. L., and DeWitt, P. W.: Synthetic temperature profiles derived from geosat altimetry: comparison with air-dropped expendable bathythermograph profiles, J. Geophys. Res., 95, 17979-17992, 1990.

Carton, J. A., Giese, B. S., Cao, X., and Miller, L.: Impact of altimeter, thermistor, and expendable bathythermograph data on restrospective analyses of the tropical Pacific Ocean, J. Geophys. Res., 101, 14147-14159, 1996.

Carton, J. A., Chepurin, G., and Cao, X.: A simple ocean data assimilation analysis of the global upper ocean 1950-95. Part I: Methodology, J. Phys. Oceanogr., 30, 294-309, 2000.

Chassignet, E. P., Hurlburt, H. E., Smedstad, O. M., Halliwell, G. R., Hogan, P. J., Wallcraft, A. J., Baraille, R., and Bleck, R.: The HYCOM (Hybrid Coordinate Ocean Model) data assimilative system, J. Marine Syst., 65, 60-83, 2007.

Ducet, N., Le Traon, P.-Y., and Reverdin, G.: Global high resolution mapping of ocean circulation from TOPEX/Poseidon and ERS-1 and -2, J. Geophys. Res., 105, 19477-19498, 2000.

Evensen, G.: The ensemble Kalman filter: theoretical formulation and practical implementation, Ocean Dynam., 53, 343-367, 2003.

Fischer, M., Flugel, M., Ji, M., and Latif, M.: The impact of data assimilation on ENSO simulations and predictions, Mon. Weather Rev., 125, 810-829, 1997.

Fujii, Y. and Kamachi, M.: Three-dimensional analysis of temperature and salinity in the equatorial Pacific using a variational method with vertical coupled temperature-salinity empirical orthogonal function modes, J. Geophys. Res., 108, 3297, doi:10.1029/2002JC001745, 2003.

Guinehut, S., Coatanoan, C., Dhomps, A.-L., Le Traon, P.-Y., and Larnicol, G.: On the use of satellite altimeter data in Argo quality control, J. Atmos. Ocean. Tech., 26, 395-402, doi:10.1175/2008JTECHO648.1, 2009.

Hurlburt, H. E.: The potential for ocean prediction and the role of altimeter data, Mar. Geod., 8, 17-66, 1984.

Ingleby, B. and Huddleston, M.: Quality control of ocean temperature and salinity profiles - historical and real-time data, J. Marine Syst., 65, 158-175, doi:10.1016/j.jmarsys.2005.11.019, 2007.

Large, W. G., McWilliams, J. C., and Doney, S. C.: Oceanic vertical mixing: a review and a model with a nonlocal boundary layer parameterization, Rev. Geophys., 32, 363-403, 1994.

Le Traon, P.-Y., Nadal, F., and Ducet, N.: An improved mapping method of multisatellite altimeter data, J. Atmos. Ocean. Tech., 15, 522-534, 1998.

Martin, M. J., Hines, A., and Bell, M. J.: Data assimilation in the FOAM operational short-range ocean forecasting system: a description of the scheme and its impact, Q. J. Roy. Meteor. Soc., 133, 981-995, 2007.

Oke, P. R, Schiller A, Griffin, D. A., and Brassington, G. B.: Ensemble data assimilation for an eddy-resolving ocean model of the Australian region, Q. J. Roy. Meteor. Soc., 131, 3301-3311, 2005.

Oke, P. R., Brassington, G. B., Griffin, D. A., and Schiller, A.: The Bluelink Ocean Data Assimilation System (BODAS), Ocean Model., 20, 46-70, doi:10.1016/j.ocemod.2007.11.002, 2008.
Oschlies, A. and Willebrand, J.: Assimilation of Geosat altimeter data into an eddy-resolving primitive equation model of the North Atlantic Ocean, J. Geophys. Res., 101, 14175-14190, 1996.

Peters, H., Gregg, M. C., and Toole, J. M.: On the parameterization of equatorialturbulence, J. Geophys. Res., 93, 1199-1218, 1988.

Reynolds, R. W., Smith, T. M., Liu, C., Chelton, D. B., Casey, K. S., and Schlax, M. G.: Daily High-resolution Blended Analyses for Sea Surface Temperature, J. Climate, 20, 5473-5496, 2007.

Rio, M.-H., Schaeffer, P., Moreaux, G., Lemoine, J.-M., and Bronner, E.: A new Mean Dynamic Topography computed over the global ocean from GRACE data, altimetry and insitu measurements, Poster communication at OceanObs09 symposium, 21-25 September 2009, Venice, available at: http://www.aviso.altimetry.fr/fileadmin/documents/data/ products/auxiliary/MDT_Cnes-CLS09_poster_Oceanobs09.pdf, 2009.

Segschneider, J., Anderson, D. L. T., and Stockdale, T. N.: Towards the use of altimetry for operational seasonal forecasting, J. Climate, 13, 3115-3138, 2000.

Smedstad, O. M., Hurlburt, H. E., and Metzger, E. J.: An operational eddy resolving $1 / 16^{\circ}$ global ocean nowcast/forecast system, J. Marine Syst., 40, 341-361, 2003.

Storto, A., Dobricic, S., Masina, S., and Di Pietro, P.: Assimilating along-track altimetric observations through local hydrostatic adjustment in a global ocean variational assimilation system, Mon. Weather Rev., 139, 738-754, 2011.

Teague, W. J., Carron, M. J., and Hogan, M. J.: A comparison between the generalized digital environmental model and levitus climatologies, J. Geophy. Res., 95, 7167-7183, 1990.

Vidard, A., Balmaseda, M., and Anderson, D.: Assimilation of altimeter data in the ECMWF ocean analysis system 3, Mon. Weather Rev., 137, 1393-1408, 2009.

Xiao, X., Wang, D., Yan, C., and Zhu, J.: Evaluation of a 3dVAR system for the South China Sea, Prog. Nat. Sci., 18, 547-554, 2008.

Xie, J. and Zhu, J.: Ensemble optimal interpolation schemes for assimilating Argo profiles into a hybrid coordinate ocean model, Ocean Model., 33, 283-298, 2010.

Xie, J., Counillon, F., Zhu, J., and Bertino, L.: An eddy resolving tidal-driven model of the South China Sea assimilating along-track SLA data using the EnOI, Ocean Sci., 7, 609-627, doi:10.5194/os-7-609-2011, 2011.

Xu, D., Zhu, J., Qi, Y., Li, X., and Yan, Y.: The impact of mean dynamic topography on a sea-level anomaly assimilation in the South China Sea based on an eddy-resolving model, Acta Oceanol. Sin., 31, 11-25, 2012.

Zheng, F., Zhu, J., and Zhang, R.: Impact of altimetry data on ENSO ensemble initializations and predictions, Geophy. Res. Lett., 34, L13611, doi:13610.11029/12007GL030451, 2007.

Zhu, J.: Overview of regional and coastal systems, Chapter 17, in: Operational Oceanography in the 21 st Century, edited by: Schiller, A. and Brassingtcu, G. B., Springer Science + Business Media B. V., the Netherlands, 413-439, 2011. 